\title{
SISTEM PENUNJANG KEPUTUSAN PEMILIHAN SUPPLIER BAHAN BAKU KERTAS DENGAN METODE QCDFR DAN ANALYTICAL HIERARCHY PROCESS : STUDI KASUS CV. ASAKA PRIMA
}

\author{
Rahmawati Alvira $^{1)}$, Rusdah ${ }^{2)}$ \\ ${ }^{1}$ Sistem Informasi, Fakultas Teknologi Informasi, Universitas Budi Luhur \\ 1,2 Jl. Raya Ciledug, Petukangan Utara, Kebayoran Lama, Jakarta Selatan 12260 \\ E-mail : rahma14alvira@gmail.com ${ }^{1)}$, rusdah@budiluhur.ac.id ${ }^{2)}$
}

\begin{abstract}
Abstrak
Supplier memiliki peran yang penting baik perusahaan ataupun individu karena Supplier pemasok yang menyediakan bahan baku. Sehingga dibutuhkannya perhitungan supaya perusahaan memperoleh Supplier sesuai dengan kebutuhan dan mendapatkan hasil terbaik agar tidak adanya terjadi kesalahan pada pemilihan Supplier karena akan mendapatkan dampak terhadap perusahaan. CV. Asaka Prima mencetak buku sehingga memerlukan Supplier bahan baku kertas. Penelitian ini bertujuan untuk memilih Supplier bahan baku kertas pada CV. Asaka Prima dengan menggunakan model kriteria Quality, Cost, Delivery, Flexibility, Responsiveness (QCDFR). Pengambilan data dilakukan dengan memberikan kuesioner kepada pemilik CV. Asaka Prima. CV.Asaka Prima belum memiliki metode perhitungan untuk memilih supplier dengan tepat yang sesuai kriteria dan subkriteria. Metode Analytical Hierarchy Process (AHP) dipilih untuk mendapatkan alternatif yang tepat agar dapat menemukan bobot kriteria dan subkriteria. Sistem penunjang keputusan ini dibuat dengan menggunakan MySql sebagai database dan php sebagai tool.
\end{abstract}

Kata kunci: Supplier, QCDFR, Analytical Hierarchy Process (AHP)

\section{PENDAHULUAN}

Supplier menjadi peran penting pada perusahaan ataupun individu karna supplier menjadi penyedia produk atau bahan baku untuk kebutuhan yang akan di jual kembali pada perusahaan atau individu. Bahan baku menjadi faktor pendukung dalam proses produksi sehingga secara langsung berpengaruh terhadap produk yang dihasilkan. Hal ini juga ada peranan dari supplier yang akan mempengaruhi kinerja perusahaan tersebut. Oleh karena itu perusahaan juga perlu mengadakan pemilihan supplier supaya sesuai dengan kebutuhan. Perusahaan juga perlu menilai supplier secara cermat dan tepat. Dilakukan penilaian supplier agar tidak terjadi dampak pada penurunan produktivitas perusahaan.

CV. Asaka Prima merupakan perusahaan yang bergerak di bidang percetakan dan penerbitan yang berskala nasional. CV. Asaka Prima mencetak buku sehingga memerlukan supplier kertas. CV. Asaka Prima melakukan penentuan supplier terbaik setiap 6 bulan sekali. CV. Asaka Prima memiliki masalah yaitu Pemilihan supplier hanya didasari oleh harga tanpa memperhatikan kesalahan yang terjadi di masa lalu sehingga diperlukan sistem yang memberikan hasil evaluasi per supplier.

Menggunakan Sistem Penunjang Keputusan memperoleh manfaat dalam pengambilan keputusan melihat dari segi aspek dan mempersingkat waktu dalam proses evaluasi kinerja supplier yang ada sehingga sistem informasi dapat berguna. Oleh sebab itu penulis merancang sebuah sistem penunjang keputusan yang dapat membantu pihak CV. Asaka Prima untuk dapat memilih supplier dengan baik dan sesuai kebutuhan perusahaan.

Pemilihan Metode Analytical Hierarchy Process (AHP) dilakukan karena penulis mengidentifikasi masalah yaitu Pemilihan supplier hanya didasari oleh harga tanpa memperhatikan kesalahan yang terjadi di masa lalu sehingga diperlukan sistem yang memberikan hasil evaluasi per supplier.

\section{STUDI LITERATUR}

\subsection{Bahan Baku}

Bahan baku merupakan komponen utamabagi industri manufaktur. Hal ini tidak terlepas dari peranan supplier sebagai penyedia bahan baku tersebut Perusahaan [1].

\subsection{Metode Analytical Hierarchy Process (AHP)}

Proses pengambilan keputusan pada dasarnya memilih suatu alternatif. Peralatan utama AHP adalah sebuah hierarki fungsional dengan input utamanya adalah persepsi manusia. Jadi perbedaan yang mencolok model AHP dengan model lainnya terletak pada jenis input-nya [2]. 


\subsection{Penelitian Sebelumnya}

Melihat dari hasil penelitian [1] jenis bahan baku menggunakan metode Analytical Hierarchy Process (AHP), memiliki kriteria Kualitas, Harga, Ketepatan Pengiriman, Flexibilitas, Layanan Pelanggan, Jaminan \& Klaim, mendapatkan hasil sistem ini hanya sebagai pendukung bagi pengguna untuk menyelesaikan permasalahan dalam memilih supplier bahan baku di CV. Sinar Agung Perkasa.

Menurut hasil penelitian [3] jenis bahan jadi menggunakan metode Perbandingan Eksponensial (MPE), memiliki kriteria akurasi, kemudahan, sistematis, biaya, nilai, tampilan. mendapatkan hasil Perhitungan dengan MPE menjelaskan bahwa teknik manajemen menggunakan aplikasi direkomendasikan sebagai teknik yang efektif dalam mengelola kedai.

Menurut hasil penelitian [4] jenis bahan jadi menggunakan Metode SAW, WP dan TOPSIS, memiliki kriteria cost, quality, quantity, dan time. Mendapatkan hasil PT SKM menjadi supplier terpilih berdasarkan perangkingan bobot, sedangkan metode WP dan TOPSIS menyatakan PT CJP menjadi supplier terpilih.

Menurut hasil penelitian [5] jenis bahan jadi menggunakan Simple Additive weighting (SAW), memiliki kriteria Jenis armada, jangkauan, pengalaman perusahaan, harga, waktu pengiriman, hasil packaging. Mendapatkan hasil Sistem yang dibangun dapat mempermudah pihak manajemen dalam menentukan keputusan pemilihan mitra jasa pengiriman barang terbaik.

\section{METODOLOGI PENELITIAN}

3.1. Metode pengumpulan data

1. Wawancara (Interview)

Wawancara dilakukan dengan direktur yaitu pemilik CV. Asaka Prima sebaga bagian yang menentukan Supplier guna memperoleh informasi dalam proses pemilihan supplier pada CV. Asaka Prima. Dokumen yang digunakan pada sistem penunjang keputusan pemilihan Supplier.

\section{Observasi}

Suatu cara mengumpulkan data melalui pengamatan dengan melakukan penglihatan secara langsung untuk mengetahui dokumen dokumen serta hal hal yang berkaitan dengan sistem yang dibuat.

3. Analisa Dokumen

Menganalisa dokumen-dokumen yang digunakan pada proses yang sedang berjalan untuk lebih jelas mengetahui cara kerja sistem.

4. Studi Pustaka

Dilakukan dengan cara membaca buku-buku, internet atau e-book yang berkaitan dengan teori seleksi Supplier, teori decision support system), teori Analytical Hierarchy Process (AHP), teori metodologi berorientasi obyek dan teori yang berkaitan dengan pembuatan sistem penunjang keputusan.

5. Instrumentasi

Pada penelitian ini penulis menggunakan teknik wawancara dan menyebarkan kuesioner sebagai intrumentasi. Wawancara dilakukan dengan pemilik CV. Asaka Prima sebagai bagian dalam memilih Supplier guna memperoleh informasi dalam proses penentuan Supplier pada CV. Asaka Prima. Informasi yang di dapat yaitu kriteria, alternatif dan proses bisnis.

\subsection{Langkah-Langkah Penelitian}

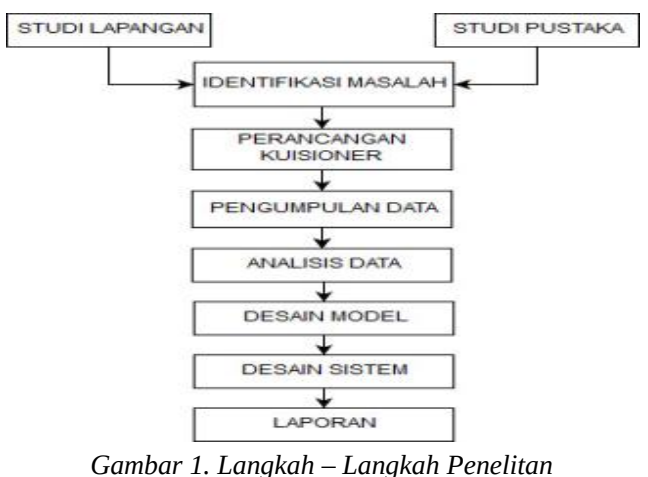

\section{HASIL DAN PEMBAHASAN}

\subsection{Tool Analisa Masalah}

Penulis menggunakan fishbone diagram karena metode ini dapat menganalisa penyebab suatu masalah (Gambar 2).

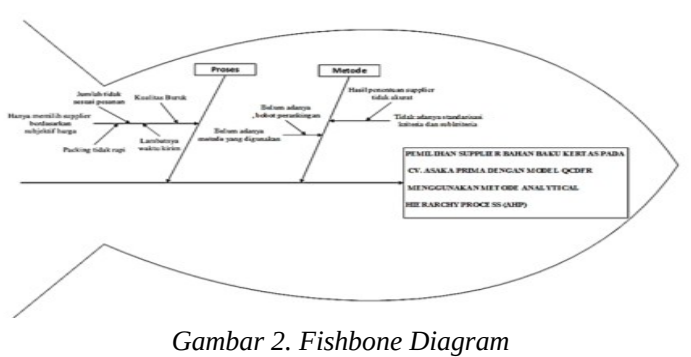

\subsection{Proses Bisnis}

CV. Asaka Prima melakukan penentuan supplier terbaik setiap 6 bulan sekali. Bagian Administrasi menelpon kepada semua supplier menanyakan harga kemudian Supplier mengirimkan daftar harga melalui e-mail setelah itu Bagian Administrasi membuat rekapitulasi daftar harga untuk setiap supplier, jika sudah dibuat Bagian Administrasi akan menyerahkan rekapitulasi daftar harga kepada Direktur lalu Direktur menentukan 
supplier terbaik berdasarkan harga termurah (Gambar 3).

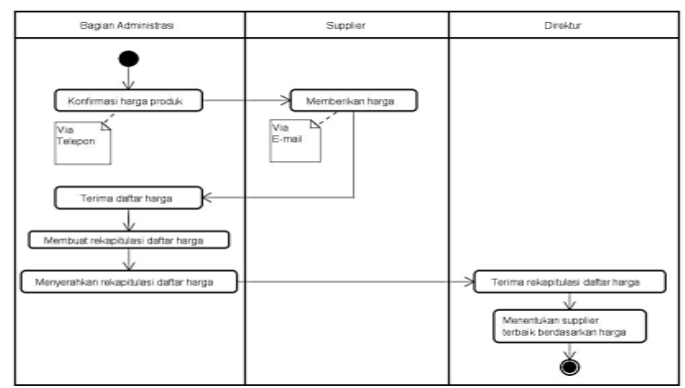

Gambar 3. Activity Diagram Proses Bisnis

\subsection{Model Analytical Hierarchy Process} (AHP)

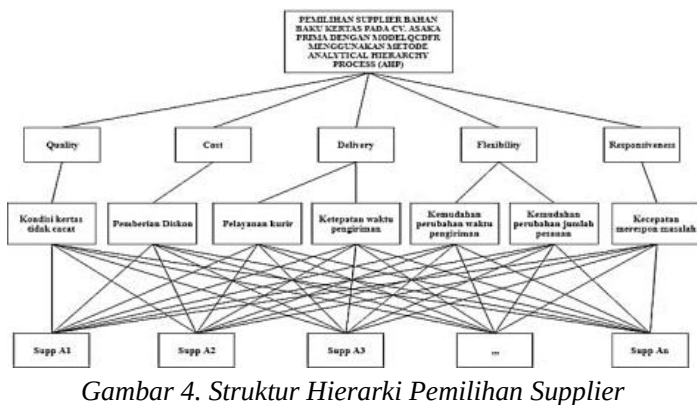

\subsection{Pengolahan Data}

a. Perbandingan Antar Kriteria

1. Menjabarkan nilai perbandingan antar kriteria menjadi matriks decimal (Gambar 5)

$\left[\begin{array}{lllll}1,0000 & 3,0000 & 4,0000 & 2,0000 & 1,0000 \\ 0,3333 & 1,0000 & 1,0000 & 0,5000 & 0,3333 \\ 0,2500 & 1,0000 & 1,0000 & 1,0000 & 1,0000 \\ 0,5000 & 2,0000 & 1,0000 & 1,0000 & 0,3333 \\ 1,0000 & 3,0000 & 1,0000 & 3,0000 & 1,0000\end{array}\right]$

Gambar 5. penjabaran matriks dalam decimal

2. Mengalikan matriks tersebut dengan dirinya sendiri sehingga adanya hasil perkalian matriks (Gambar 6)

$\left(\begin{array}{rrrrr}5,0000 & 17,0000 & 14,0000 & 12,5000 & 7,6667 \\ 1,5000 & 5,0000 & 4,1667 & 3,6667 & 2,1667 \\ 2,3333 & 7,7500 & 5,0000 & 6,0000 & 2,9167 \\ 2,2500 & 7,5000 & 6,3333 & 5,0000 & 2,8833 \\ 4,7500 & 16,0000 & 12,0000 & 10,5000 & 5,0000\end{array}\right)$

Gambar 6. hasil perkalian matriks

3. Menjumlahkan setiap baris dari hasil perkalian matriks iterasi ke 1 (Gambar 7)

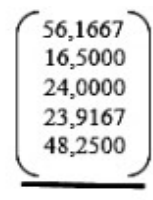

168,8333

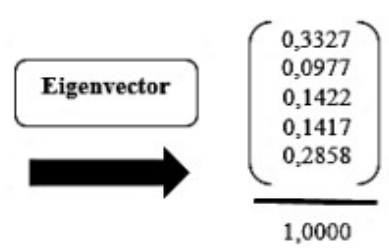

1,0000
Gambar 7. Eigenvector antar kriteria

b. Perbandingan Antar Subkriteria

1. Menjabarkan nilai perbandingan antar sukriteria menjadi matriks decimal (gambar 8)

\section{$\left[\begin{array}{ll}1,0000 & 0,2000 \\ 5,0000 & 1,0000\end{array}\right]$ \\ Gambar 8. penjabaran matriks dalam decimal}

2. Mengalikan matriks tersebut dengan dirinya sendiri sehingga adanya hasil perkalian matriks (Gambar 9)

$$
\begin{gathered}
{\left[\begin{array}{cc}
\mathbf{2}, 0000 & 0,4000 \\
\mathbf{1 0}, 0000 & \mathbf{2}, \mathbf{0 0 0 0}
\end{array}\right]} \\
\text { Gambar 9. hasil perkalian } \\
\text { matriks }
\end{gathered}
$$

3. Menjumlahkan setiap baris dari hasil perkalian matriks iterasi ke 1 (Gambar 10).

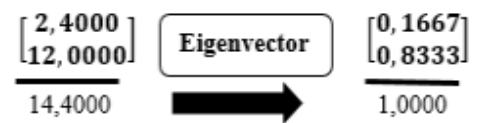

Gambar 10. Eigenvector antar subkriteria

c. Perbandingan Alternatif

1. Menjabarkan nilai perbandingan alternatif sukriteria kualitas kertas menjadi matriks decimal (gambar 11)

$$
\left[\begin{array}{lllll}
1,0000 & 5,0000 & 2,0000 & 3,0000 & 1,0000 \\
0,2000 & 1,0000 & 0,3333 & 0,3333 & 0,5000 \\
0,5000 & 3,0000 & 1,0000 & 1,0000 & 1,0000 \\
0,3333 & 3,0000 & 1,0000 & 1,0000 & 1,0000 \\
1,0000 & 2,0000 & 1,0000 & 1,0000 & 1,0000
\end{array}\right]
$$

Gambar 11. penjabaran matriks dalam decimal

2. Mengalikan matriks tersebut dengan dirinya sendiri sehingga adanya hasil perkalian matriks (Gambar 12)

$\left(\begin{array}{rrrrr}5,0000 & 27,0000 & 9,6667 & 10,6667 & 9,5000 \\ 1,1778 & 5,0000 & 1,9000 & 2,1000 & 1,8667 \\ 2,9333 & 13,5000 & 5,0000 & 5,5000 & 5,0000 \\ 2,7667 & 12,6667 & 4,6667 & 5,0000 & 4,8333 \\ 3,2333 & 18,0000 & 5,6667 & 6,6667 & 5,0000\end{array}\right)$

Gambar 12. hasil perkalian matriks 
3. Menjumlahkan setiap baris dari hasil perkalian matriks iterasi ke 1

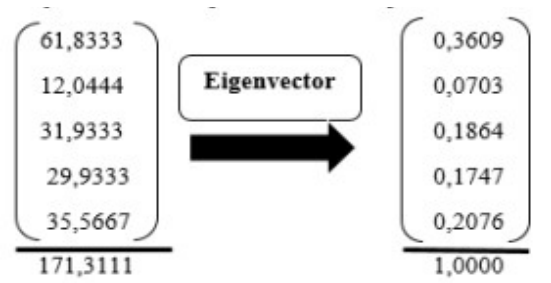

Gambar 13. Eigenvector perbandingan alternatif subkriteria kualitas kertas

4. Menjabarkan nilai perbandingan alternatif sukriteria pemberian diskon menjadi matriks decimal (gambar 14)

$\left[\begin{array}{lllll}1,0000 & 0,2000 & 0,3333 & 0,5000 & 1,0000 \\ 5,0000 & 1,0000 & 1,0000 & 2,0000 & 1,0000 \\ 3,0000 & 1,0000 & 1,0000 & 2,0000 & 3,0000 \\ 2,0000 & 0,5000 & 0,5000 & 1,0000 & 1,0000 \\ 1,0000 & 1,0000 & 0,3333 & 1,0000 & 1,0000\end{array}\right]$

Gambar 14. penjabaran matriks dalam decimal

5. Mengalikan matriks tersebut dengan dirinya sendiri sehingga adanya hasil perkalian matriks (Gambar 15)

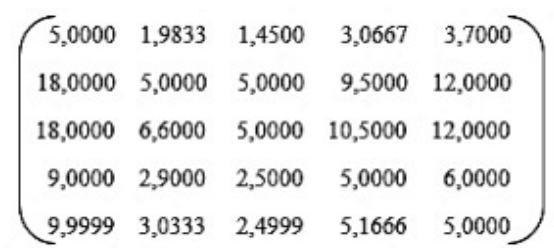

Gambar 15. hasil perkalian matriks

6. Menjumlahkan setiap baris dari hasil perkalian matriks iterasi ke 1 (Gambar 16)

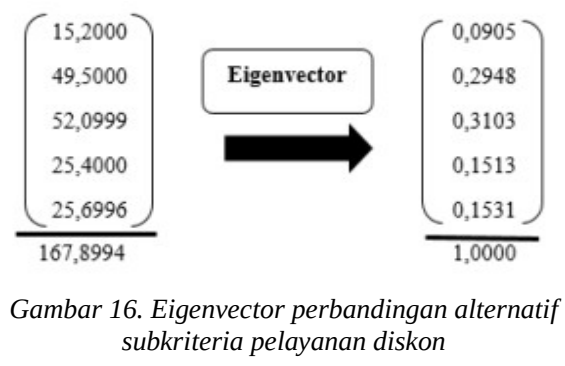

d. Perankingan Alternatif

Hasil perangkingan yang didapat dari bobot subkriteria dan bobot alternatif untuk memilih supplier :
Tabel 1. Perankingan Alternatif

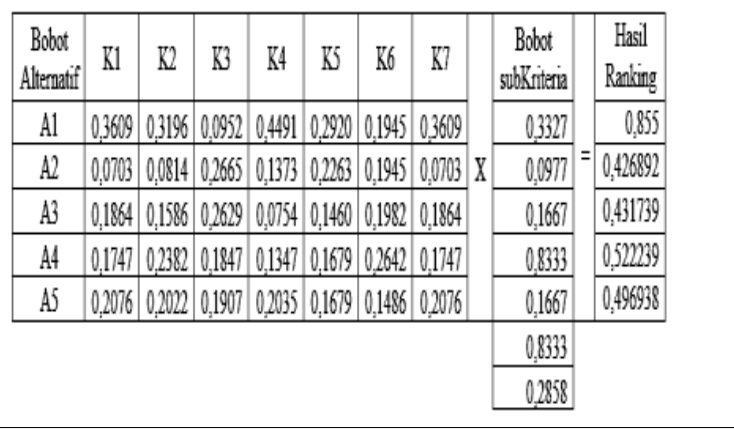

Dapat disimpulkan berdasarkan perankingan alternatif pada A1 PT. Buana Paper Poris mendapatkan hasil 0,8555, A2 Toko Kertas Kharisma mendapatkan hasil 0,426892, A3 Toko Kertas Bintang mndapatkan hasil 0,431739, A4 Toko Kertas Bintang mendapatkan hasil 0,431739, A5 Toko Kertas Anom mendapatkan hasil 0,522239, dan A5 Toko Kertas Karawaci mendapatkan hasil 0,496938 sehingga dapat dilihat bahwa PT. Buana Paper Poris menjadi supplier terpilih.

\subsection{Hasil Penelitian}

Tabel 2. Hasil Penelitian

\begin{tabular}{|l|l|}
\hline \multicolumn{1}{|c|}{ Nama Alternatif } & Nilai Alternatif \\
\hline PT. Buana Paper Poris & 0,855 \\
\hline Toko Kertas Kharisma & 0,426892 \\
\hline Toko Kertas Bintang & 0,431739 \\
\hline Toko Kertas Anom & 0,522239 \\
\hline Toko Kertas Karawaci & 0,496938 \\
\hline
\end{tabular}

Dari 5 (lima) supplier yang ada berdasarkan Perankingan Alternatif yang mempunyai nilai 0,855 yang menjadi supplier terpilih adalah PT. Buana Paper Poris.

Tabel 3. Hasil Penelitian QCDFR

\begin{tabular}{|l|l|}
\hline \multicolumn{1}{|c|}{ Kriteria } & Hasil Nilai \\
\hline Quality & 0,3327 \\
\hline Cost & 0,0977 \\
\hline Delivery & 0,1422 \\
\hline Flexibility & 0,1417 \\
\hline Responsiveness & 0,2858 \\
\hline
\end{tabular}

Dari 5 (lima) supplier yang ada berdasarkan Perhitungan QCDFR yang sangat brpengaruh mempunyai nilai 0,3327 adalah kriteria Quality dengan subkriteria kualitas kertas tidak cacat. 


\subsection{Use Case Diagram}

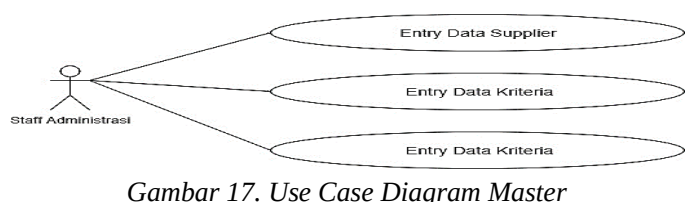

Use Case Diagram digunakan untuk menampilkan fungsi-fungsi pada SPK yang diusulkan. Gambar 17 adalah fungsi untuk memasukkan data master, yaitu Entry Data Supplier, Entry Data Kriteria dan Entry Data Kriteria.

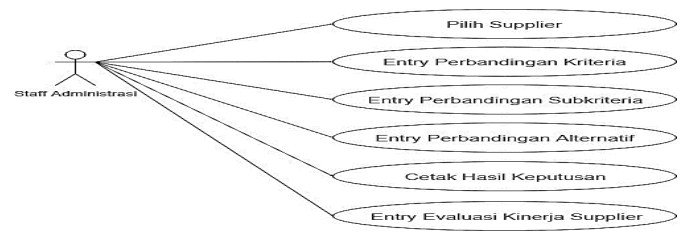

Gambar 18. Use Case Diagram Transaksi

Use Case Diagram digunakan untuk menampilkan fungsi-fungsi pada SPK yang diusulkan. Gambar 18 adalah fungsi untuk memasukkan data transaksi, yaitu Pilih Supplier, Entry Perbandingan Kriteria, Entry Perbandingan Subkriteria, Entry Perbandingan Alternatif, Cetak Hasil Keputusan dan Entry Evaluasi Kinerja Supplier.

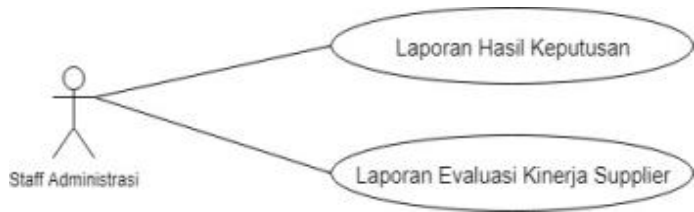

Gambar 19. Use Case Diagram Laporan

Use Case Diagram digunakan untuk menampilkan fungsi-fungsi pada SPK yang diusulkan. Gambar 19 adalah fungsi untuk mencetak Laporan Hasil Keputusan, dan Laporan Evaluasi Kinerja Supplier.

\subsection{Perancangan Database}

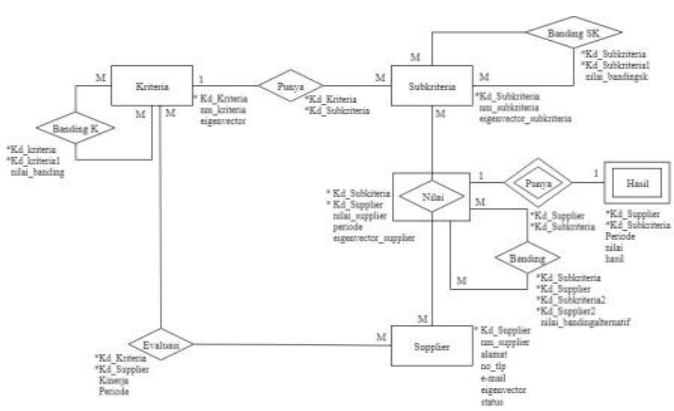

Gambar 20. Entity Relationship Diagram

\subsection{Rancangan Layar}

a. Menu Utama

Pada saat sistem dijalankan akan menampilkan menu utama Gambar 21 Terdapat menu Data master, menu Data transaksi, dan menu Data laporan yang masing-masing menu terdapat sub menu.

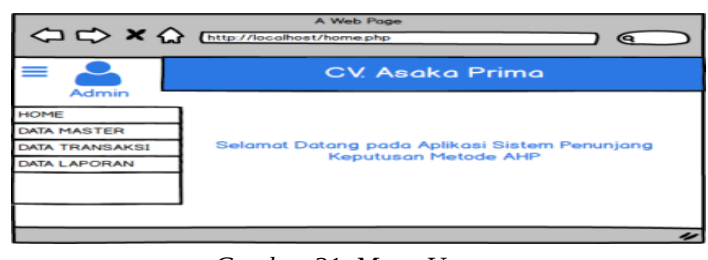

Gambar 21. Menu Utama

b. Menu Master Data Supplier

Halaman web ini berupa form untuk menginput data supplier (Gambar 22).

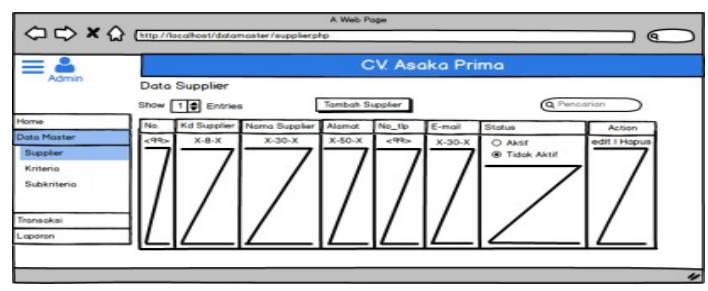

Gambar 22. Menu Master Data Supplier

c. Menu Transaksi Entry Perbandingan Kriteria

Pada Menu Entry Perbandingan kriteria pilih kriteria pada combo box pilih nama kriteria kemudian masukkan nilai kriteria 1 dengan combo box dan nilai 2 dimasukan dengan manual kemudian pilih selanjutnya.

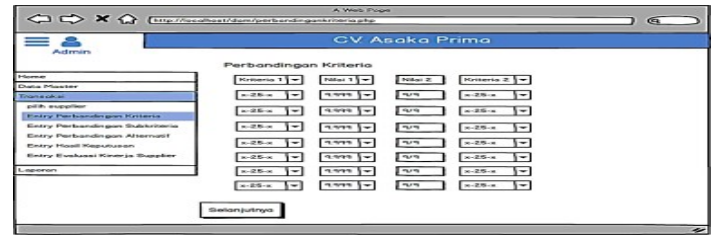

Gambar 23. Entry Perbandingan Kriteria

\section{d. Menu Cetak Laporan Hasil Keputusan}

Jika sudah mengentry hasil keputusan pada menu transaksi untuk mencetak laporan pilih cetak laporan hasil keputusan kemudian pilih periode lalu pilih cetak (Gambar 24).

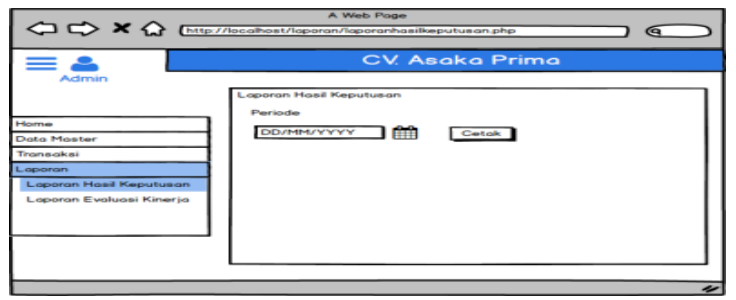

Gambar 24. Rancangan Layar Cetak Laporan Hasil Keputusan 
e. Menu Cetak Laporan Evaluasi Kinerja Supplier

Jika sudah mengentry evaluasi kinerja supplier pada menu transaksi untuk mencetak laporan pilih cetak laporan evaluasi keputusan kemudian pilih periode lalu pilih cetak (Gambar 25).

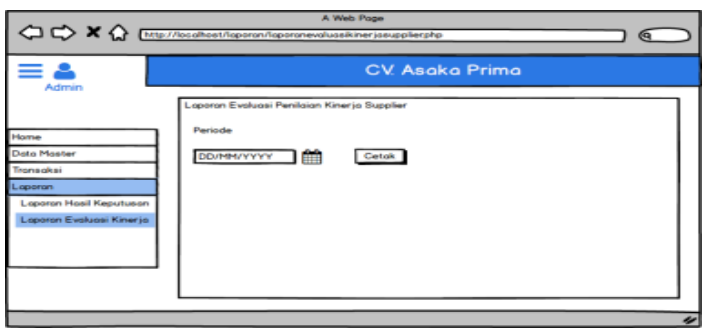

Gambar 25. Rancangan Layar Cetak Laporan Evaluasi Kinerja Supplier

\subsection{Struktur Menu}

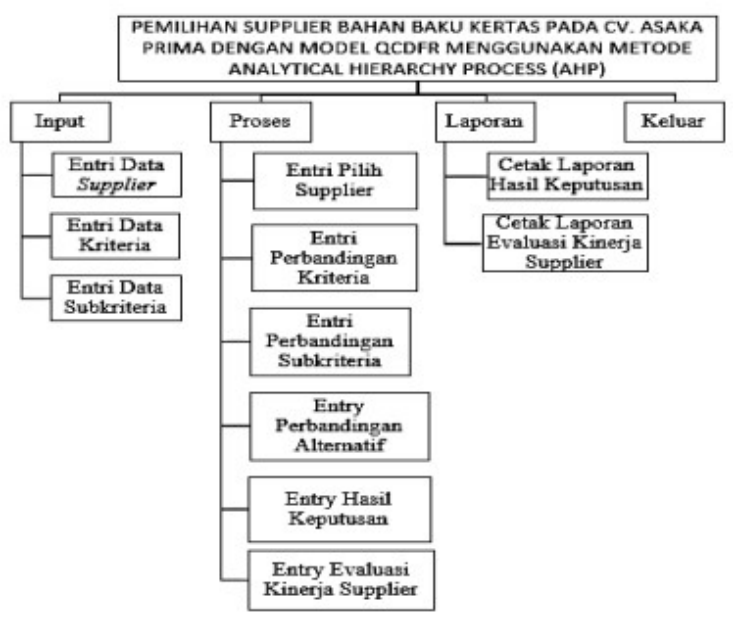

Gambar 26. Struktur Menu

\section{KESIMPULAN}

Berdasarkan analisa yang telah dilakukan pada bab-bab sebelumnya dapat ditarik kesimpulan sebagai berikut :

a) Dengan adanya sistem penunjang keputusan ini dapat membantu CV. Asaka Prima dalam mengambil keputusan untuk memilih supplier.

b) Dengan adanya fitur entry evaluasi kinerja supplier pada sistem penunjang keputusan dapat memudahkan pihak CV. Asaka Prima dalam melihat kinerja supplier sebelumnya sebagai dasar pengambilan keputusan berikutnya.

c) Dengan adanya sistem penunjang keputusan CV. Asaka Prima dapat dengan mudah melihat data transaksi sebelumnya, menginput data dan membuat laporan.

\section{DAFTAR PUSTAKA}

[1] K. W. Haryanto and S. A. Sadeyah, "Sistem Pendukung Keputusan Pemilihan Supplier Bahan Baku Pada Cv . Sinar Agung Perkasa Menggunakan,” vol. 10, no. 2, pp. 1-8, 2018.

[2] S. Rahmatullah and A. Rifai, "Penerapan Metode Analtical Hierarchy Process Dalam Memilih Bahan Bakar Minyak Untuk,” J. Kaji. Ilm., vol. 18, no. 1, pp. 1-8, 2018.

[3] D. R. Wardhani and R. Abdillah, "Pengambilan Keputusan Dengan Metode Perbandingan Eksponensial ( Mpe ) Dalam Manajemen Kedai,” no. 2004, pp. 1-6, 2018.

[4] A. nurul, putiri, "Pemilihan Supplier Material Berdasarkan Multi Attribute Decision Making (MADM) Dengan Menggunakan Metode SAW, WP dan TOPSIS (Studi Kasus di PT XYZ),” J. Tek. Ind. Untirta, vol. 1, no. 3, pp. 200-205, 2013.

[5] T. Y. Akhirina, "Sistem Pendukung Keputusan Pemilihan Mitra Jasa Pengiriman Barang Menggunakan Metode SAW," Jupiter, vol. 2, no. Sistem Pendukung Keputusan, pp. 1-10, 2012. 